\title{
Marine Environmental Radioactivity Near Nuclear Power Plants in Northern Taiwan
}

Chih-An Huh

Research Fellow, Institute of Earth Sciences, Academia Sinica, Taipei, Taiwan, R.O.C., huh@earth.sinica.edu.tw

Chih-Chieh Su

Assistant Professor, Institution of Oceanography, National Taiwan University, Teipei, Taiwan, R.O.C.

Yueh-Yuan Tu

Director, Department of industrial Safety and Environmental Protection, Taipower Company, Taipei, Taiwan, R.O.C.

Kwang-Tsao Shao

Research Fellow, Institute of Zoology, Academia Sinica, Taipei, Taiwan, R.O.C.

Ching-Yi Chen

Research Fellow, Institute of Zoology, Academia Sinica, Taipei, Taiwan, R.O.C.

See next page for additional authors

Follow this and additional works at: https://jmstt.ntou.edu.tw/journal

Part of the Terrestrial and Aquatic Ecology Commons

\section{Recommended Citation}

Huh, Chih-An; Su, Chih-Chieh; Tu, Yueh-Yuan; Shao, Kwang-Tsao; Chen, Ching-Yi; and Cheng, I-Jiunn (2004) "Marine Environmental Radioactivity Near Nuclear Power Plants in Northern Taiwan," Journal of Marine Science and Technology: Vol. 12: Iss. 5, Article 8.

DOI: $10.51400 / 2709-6998.2263$

Available at: https://jmstt.ntou.edu.tw/journal/vol12/iss5/8

This Research Article is brought to you for free and open access by Journal of Marine Science and Technology. It has been accepted for inclusion in Journal of Marine Science and Technology by an authorized editor of Journal of Marine Science and Technology. 


\section{Marine Environmental Radioactivity Near Nuclear Power Plants in Northern}

Taiwan

\section{Acknowledgements}

We are indebted to the collaboration of other components of this environmental monitoring program and the program coordinator, Prof. J.-S. Hwang. The fish samples were ashed at the Radiation Laboratory of Taiwan Power Company. S.-Y. Lee, S.-F. Lu, Y.-S. Tong, C.-Y. Ling, S.-T. Ho, L.-J. Shiao and Y.-K. Cheng assisted in field sampling and laboratory work. This work is supported by Taiwan Power Company.

\section{Authors}

Chih-An Huh, Chih-Chieh Su, Yueh-Yuan Tu, Kwang-Tsao Shao, Ching-Yi Chen, and I-Jiunn Cheng 


\title{
MARINE ENVIRONMENTAL RADIOACTIVITY NEAR NUCLEAR POWER PLANTS IN NORTHERN TAIWAN
}

\author{
Chih-An Huh*, Chih-Chieh Su**, Yueh-Yuan Tu***, Kwang-Tsao Shao****, \\ Ching-Yi Chen****, and I-Jiunn Cheng*****
}

Key words: environmental radioactivity, nuclear power plants, natural and artificial radionuclides, northern Taiwan.

\section{ABSTRACT}

The levels and composition of environmental radioactivity at the outlets of nuclear power plants and nearby coastal environs in northern Taiwan have been investigated by gamma spectrometric analysis of seawater, algae, fish and sediment samples collected systematically in the past four years. The results show that anthropogenic radionuclides contribute very little to the total radioactivities in all types of samples. Samples from the outlet of the Second Nuclear Power Plant are more enriched in artificial nuclides, with average algae samples containing $\sim 4 \mathrm{~Bq} / \mathrm{kg}$ of ${ }^{137} \mathrm{Cs}+{ }^{54} \mathrm{Mn}+{ }^{60} \mathrm{Co}$ (or $3.6 \%$ of the total activity) and average sediment samples containing $\sim 6 \mathrm{~Bq} / \mathrm{kg}$ of ${ }^{137} \mathrm{Cs}+{ }^{54} \mathrm{Mn}+{ }^{60} \mathrm{Co}$ (or $1 \%$ of the total activity). Compared with AEC-mandated investigation levels of ${ }^{137} \mathrm{Cs},{ }^{54} \mathrm{Mn}$ and ${ }^{60} \mathrm{Co}$ for various types of environmental materials, average activities of these artificial nuclides observed to date are two to three orders of magnitude lower, well within their regulatory limits.

The ultimate source of ${ }^{137} \mathrm{Cs}$ in the survey area is most likely atmospheric fallout derived from weapons tests during the 1950's and 1960 's. As regards ${ }^{54} \mathrm{Mn}$ and ${ }^{60} \mathrm{Co}$, they were inevitably emitted from nuclear power pants, largely during or after the period of power outages for scheduled maintenance of reactors. Thus far, we have not detected any traces of ${ }^{54} \mathrm{Mn}$ and ${ }^{60} \mathrm{Co}$ beyond the outlets of the first and the second nuclear power plants, suggesting that the dispersal of reactor-produced artificial nuclides is highly restricted and well controlled.

\section{INTRODUCTION}

Of the three nuclear power plants in operation in

Paper Submitted 10/05/04, Accepted 11/30/04. Author for Correspondence: Chih-AnHuh.E-mail: huh@earth.sinica.edu.tw.

*Research Fellow, Institute of Earth Sciences, Academia Sinica, Taipei, Taiwan, R.O.C.

**Assistant Professor, Institution of Oceanography, National Taiwan University, Teipei, Taiwan, R.O.C.

***Director, Department of industrial Safety and Environmental Protection, Taipower Company, Taipei, Taiwan, R.O.C.

**** Research Fellow, Institute of Zoology, Academia Sinica, Taipei, Taiwan, R.O.C.

***** Professor, Institute of Marine Biology, National Taiwan Ocean University, Keeling, Taiwan, R.O.C.
Taiwan, the first two (NPP-1 and NPP-2) are located along the northernmost coast and the third one (NPP-3) on the southernmost coast of Taiwan. In addition, the fourth nuclear power plant (NPP-4) sited at the northeast corner of Taiwan, is currently under construction. According to Taiwan's environmental protection law, the potential impact of any power plant to its surrounding environment must be assessed during its planning stage and monitored continuously during its operational stage to verify that relevant requirements are fulfilled. Since all nuclear power plants on the island are located adjacent to the sea so as to use seawater to cool their reactors, the impact of warm effluent water discharged from their outlets to the coastal environment is an issue of prime concern.

As a component of a research consortium, our objective is to monitor the levels and composition of environmental radioactivity at the outlets of NPP-1, 2 and 4 and nearby coastal environments in northern Taiwan. It is most important to scrutinize the release of artificial radionuclides from the plants, to quantify its contribution to the radioactivity levels in environmental samples, to examine the spatial distribution and temporal trend, and to determine if at all it could pose any radiation impact on the environment. We address these questions by targeting at four types of samples most representative of the marine ecosystem: seawater, algae, fish and sediments. Using gamma spectrometry, various natural and anthropogenic radionuclides in the samples were analyzed. Here, we summarize the results obtained in the past four years.

\section{MATERIALS AND METHODS}

\section{Sampling time and place}

Field sampling was conducted every season to collect algae and sediment samples at the outlets of NPP- 1 and 2 and the inter-tidal zone at the construction site of NPP-4. Fish samples were caught nearshore 
close to the three plants. Additional sediment samples were collected off the inter-tidal zone by scuba diving near the inlets and outlets of the plants. Besides seasonal sampling, algae and sediment samples were also collected from the outlets of NPP-1 and NPP-2 following power outages for scheduled maintenance of reactors. Figure 1 shows the location of the plants and the sampling sites.

\section{Sample preparation}

Fish and algae samples were cleaned (to remove attached and trapped particles), weighed, and identified of their species shortly after collection. Following drying at $90^{\circ} \mathrm{C}$ and ashing at $550^{\circ} \mathrm{C}$, the ash samples were weighed and transferred to counting jars for gamma spectrometry. Sediment samples were prepared for counting by drying at $90^{\circ} \mathrm{C}$ and transferring to counting jars. Seawater samples (of $\sim 30-40$ liters) collected from the outlets of NPP-1 and NPP-2 were processed for the determination of ${ }^{137} \mathrm{Cs}$ according to the procedures described in $\mathrm{Su}$ et al. (2000).

\section{Gamma spectrometry}

Seven natural and three anthropogenic radionu-
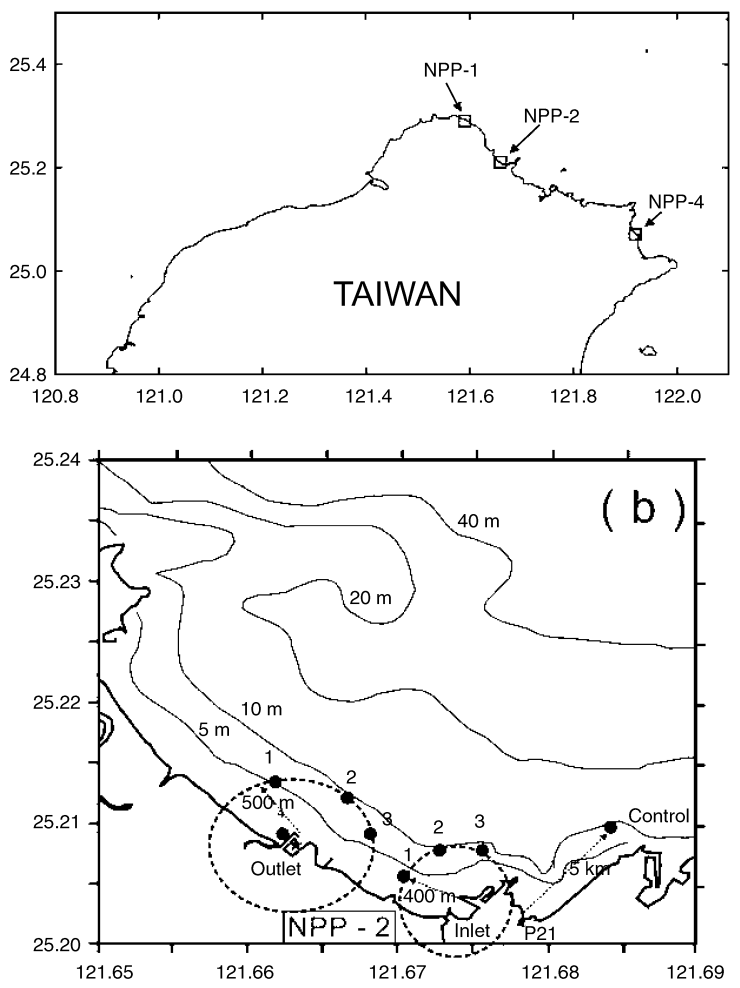

clides were determined using a $150 \%$ efficiency (relative to $3 \times 3 \mathrm{NaI}$ ) $\mathrm{HPGe}$ detector (EG\&G ORTEC GEM150230) interfaced to a digital gamma-ray spectrometer $\left(\mathrm{DSPec}^{\circledR}\right)$. These nuclides (and their respective photon energies of interests) are ${ }^{7} \mathrm{Be}(477.56 \mathrm{keV}),{ }^{40} \mathrm{~K}$ $(1460.75 \mathrm{keV}),{ }^{228} \mathrm{Ac}(911.07 \mathrm{keV}),{ }^{214} \mathrm{~Pb}(351.99 \mathrm{keV})$, ${ }^{214} \mathrm{Bi}(609.32 \mathrm{keV}),{ }^{212} \mathrm{~Pb}(238.63 \mathrm{keV}),{ }^{208} \mathrm{Tl}(583.14$ $\mathrm{keV}),{ }^{137} \mathrm{Cs}(661.62 \mathrm{keV}),{ }^{54} \mathrm{Mn}(834.82 \mathrm{keV})$ and ${ }^{60} \mathrm{Co}$ (1332.51 keV).

Efficiency calibration of the detector was performed using IAEA reference materials 133A, 327 and 375, followed by Rock-falling Mountain soils issued by the Radiation Monitoring Center of the Atomic Energy Council, Taiwan. The latter, because of its ample quantity and hence convenience for manipulation, was used as a secondary standard for mass calibration. At the ${ }^{137} \mathrm{Cs}$ peak $(661.62 \mathrm{keV})$, for example, the absolute counting efficiency for our samples (in plastic jars of $8.5-\mathrm{cm}$ diameter, $7.5-\mathrm{cm}$ height) varied from $6.35 \%$ for 20 -gram samples to $3.53 \%$ for 250 -gram samples, and the peak resolution was $1.21 \mathrm{keV}$ (FWHM) with a peakto-Compton ratio higher than 90. Shown in Fig. 2 are the efficiency curves thus determined for the abovementioned nuclides expressed as functions of sample mass in the range from 20 to $250 \mathrm{~g}$. Figure 3 is a sample spectrum showing peaks of the nuclides of interest.

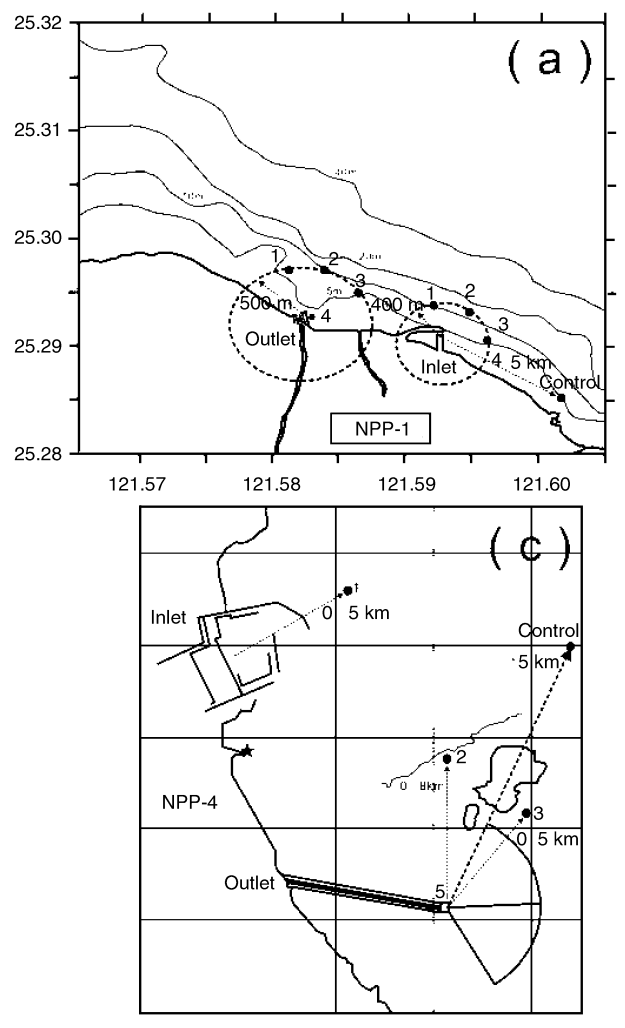

Fig. 1. Sampling sites near (a) NPP-1, (b) NPP-2, and (c) the construction site of NPP-4. The stars represent sites for algae sampling and the numbered dots represent locations for sediment sampling. 
After subtracting background counts, Nuclide activities $(A$; in $\mathrm{Bq} / \mathrm{kg})$ are calculated by: $A=N / E / I / \Delta t / W$, where $N$ is the number of net counts accumulated in the peak region of interest (ROI), $E$ is the counting efficiency for the nuclide of interest, $\Delta t$ is the counting time (in seconds) elapsed and $W$ is sample mass (in $\mathrm{kg}$ ). It is important to note here that, for biological samples, $W$ in the equation is ash weight, but the calculated results must be converted to $\mathrm{Bq} / \mathrm{kg}$ in fresh weight for reporting. The reported activities have been decay-corrected to the time of sample collection.

The counting time varied from hours to days depending on sample size and radioactivity level in each individual sample. Backgrounds of the counting system were monitored periodically by counting an empty counting jar. We followed EML's convention for the lower limit of detection (LLD $=4.66 S_{b}$, where $S_{b}$ is the uncertainty in terms of $1 \sigma$ for background measurements). If the calculated nuclide activities fall below LLD, they are reported as "not detectable".

\section{RESULTS AND DISCUSSION}

We have in the past four years analyzed 41 fish samples, 73 algae samples and 158 sediment samples, in addition to 3 seawater samples collected and studied prior to September 2000. The complete data sets and further details about the samples can be found in our annual reports (Hwang et al., 2000-2004). Here, we organize the data into eleven groups based on the types and locations of samples for an overview. Mean activities are calculated for each type/group and listed in Table 1 for the following discussion.

\section{Levels of radioactivity and composition of radionu- clides in various types/groups of samples}

Table 1 shows that naturally occurring radionu-

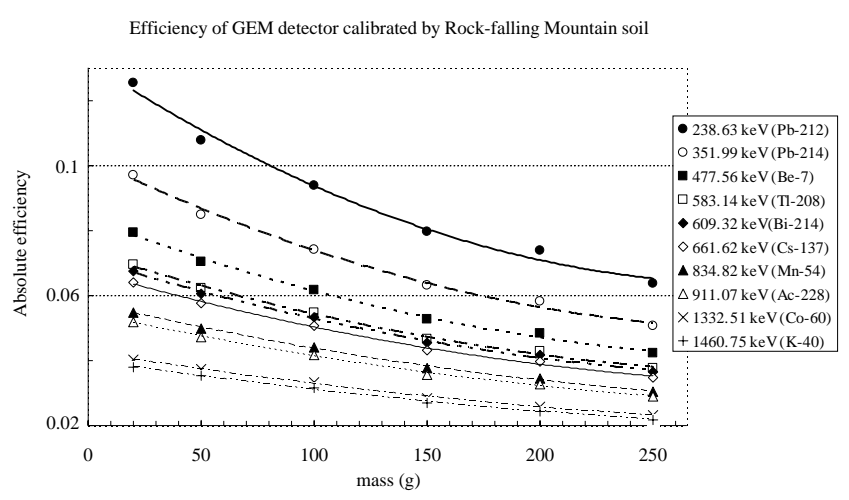

Fig. 2. Efficiency curves for nuclides of interest expressed as functions of sample mass in the range from 20 to $250 \mathrm{~g}$. clides constitute bulk of the radioactivities in all types of samples. Among the natural nuclides measured, ${ }^{40} \mathrm{~K}$ is by far the most abundant one, followed by ${ }^{232} \mathrm{Th}$-series nuclides, ${ }^{238} \mathrm{U}$-series nuclides and ${ }^{7} \mathrm{Be}$.

An attempt was made to estimate total activities in various types of samples. It is done by assuming that, in all samples, ${ }^{228} \mathrm{Ac}\left(T_{1 / 2}=6.15 \mathrm{~h}\right)$ is in equilibrium with ${ }^{228} \mathrm{Ra}\left(T_{1 / 2}=5.75 \mathrm{y}\right)$ and all short-lived nuclides following ${ }^{228} \mathrm{Th}\left(T_{1 / 2}=1.91 \mathrm{y}\right)$ are in radioactive equilibrium. Thus, total activity of the ${ }^{232} \mathrm{Th}$-series nuclides can be roughly estimated by: $\Sigma^{232} \mathrm{Th}$-series $=2 \times{ }^{228} \mathrm{Ac}+7 \times$ ${ }^{212} \mathrm{~Pb}$. Similarly, by assuming all short-lived nuclides following the longer-lived ${ }^{226} \mathrm{Ra}\left(T_{1 / 2}=1600 \mathrm{y}\right)$ are in secular equilibrium, total activity of the ${ }^{238} \mathrm{U}$-series nuclides is approximately calculated by: $\Sigma^{238} \mathrm{U}$-series = $9 \times{ }^{214} \mathrm{~Pb}$. Average "total" activities thus calculated for various types of samples collected over the four-year period are in the order: sediment $(619 \mathrm{~Bq} / \mathrm{kg})>$ algae $(123 \mathrm{~Bq} / \mathrm{kg})>$ fish $(113 \mathrm{~Bq} / \mathrm{kg})>$ seawater $(12 \mathrm{~Bq} / \mathrm{kg})$. Because some nuclides (e.g., uranium isotopes and excess ${ }^{210} \mathrm{~Pb}$ ) are not considered in the above calculation, these are likely underestimated values for total radioactivity. Although the calculation is only semiquantitative, for the sake of environmental protection, it is still a useful way for comparing the relative magnitude of radiation levels in various types of environmental samples and between natural and anthropogenic radionuclides.

A schematic presentation of the composition of nuclides and relative magnitude of average "total" activities in these four types of samples is shown in Fig. 4. Our calculation shows that the three anthropogenic nuclides $\left({ }^{54} \mathrm{Mn},{ }^{60} \mathrm{Co}\right.$ and $\left.{ }^{137} \mathrm{Cs}\right)$ combined account for a very small fraction $(<4 \%$ or much less) of the calculated total activities (Table 1).

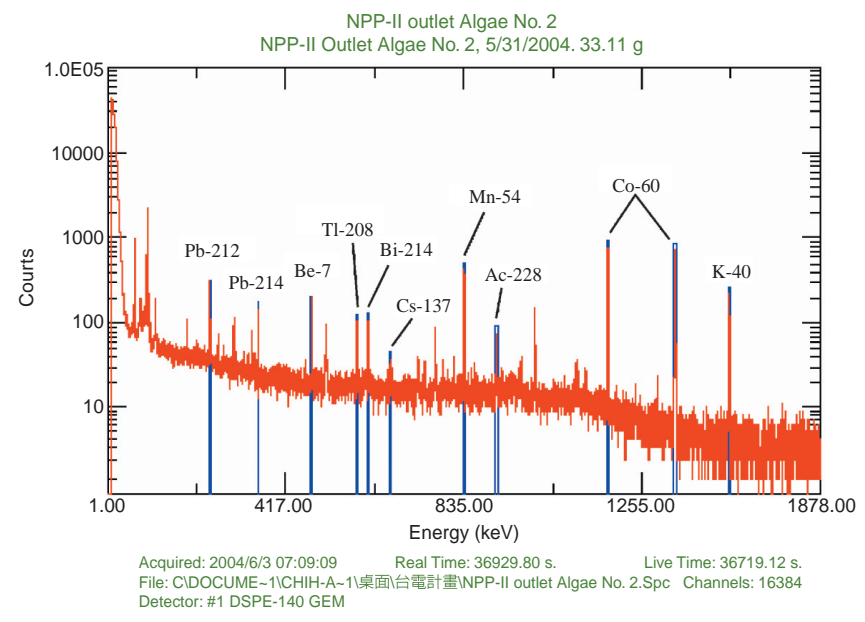

Fig. 3. A sample gamma spectrum showing peaks of the nuclides of interest. 


\section{Anthropogenic radionuclides}

(1) ${ }^{137} \mathrm{Cs}$

${ }^{137} \mathrm{Cs}$ is often detectable in the collected samples, with average activities of $0.0024,0.09,0.21$ and 0.32 $\mathrm{Bq} / \mathrm{kg}$ in seawater, algae, fish and sediment samples, respectively. These represent only $0.02-0.2 \%$ of the total activities in their host materials and are $0.12 \%$, $0.11 \%, 0.28 \%$ and $1.6 \%$ of AEC-mandated investigation levels for ${ }^{137} \mathrm{Cs}$ in seawater, algae, fish and sediment samples, respectively (Table 2). The increase of ${ }^{137} \mathrm{Cs}$ concentration from seawater to the biota suggests bio-concentration factors of 35 and 86 for algae and fish samples, respectively.

Sedimentary ${ }^{137} \mathrm{Cs}$ activities found here are lower

Table 1. Mean activities ( $\mathrm{Bq} / \mathrm{kg}$ )a of radionuclides in various types/groups of environmental samples collected along the northern coast of Taiwan near the outlets of Nuclear Power Plants (NPP-1 and -2) and the construction site of NPP-4

\begin{tabular}{|c|c|c|c|c|c|c|c|c|c|c|c|}
\hline \multirow{2}{*}{$\begin{array}{c}\text { Sample type/group } \\
\text { (\# samples analyzed) }\end{array}$} & ${ }^{7} \mathrm{Be}$ & ${ }^{40} \mathrm{~K}$ & ${ }^{228} \mathrm{Ac}$ & ${ }^{214} \mathrm{~Pb}$ & ${ }^{214} \mathrm{Bi}$ & ${ }^{212} \mathrm{~Pb}$ & ${ }^{208} \mathrm{Tl}$ & ${ }^{137} \mathrm{Cs}$ & ${ }^{54} \mathrm{Mn}$ & ${ }^{60} \mathrm{Co}$ & $\Sigma A^{b}$ \\
\hline & \multicolumn{11}{|c|}{$\mathrm{Bq} / \mathrm{kg}$} \\
\hline Seawater (3) & $-{ }^{d}$ & 11.5 & - & 0.02 & 0.02 & - & - & 0.002 & - & - & $11.8^{\mathrm{c}}$ \\
\hline \multicolumn{12}{|l|}{ Algae } \\
\hline NPP-1 outlet (20) & 2.5 & 90 & 3.8 & 2.4 & 2.7 & 4.3 & 2.9 & 0.09 & 0.5 & 0.6 & 152 \\
\hline NPP-2 outlet (46) & 6.0 & 63 & 1.9 & 1.3 & 1.3 & 2.5 & 1.7 & 0.09 & 1.2 & 2.6 & 106 \\
\hline NPP-4 site (7) & 2.2 & 143 & 0.6 & 0.5 & 0.5 & 0.6 & 0.4 & 0.05 & - & - & 155 \\
\hline \multicolumn{12}{|l|}{ Fish } \\
\hline Near NPP-1 outlet (15) & 1.0 & 93 & 0.5 & 0.4 & 0.4 & 0.4 & 0.2 & 0.09 & - & - & 116 \\
\hline Near NPP-2 outlet (13) & 1.7 & 140 & 0.5 & 0.3 & 0.4 & 0.4 & 0.1 & 0.2 & - & - & 162 \\
\hline Near NPP-4 site (13) & 0.4 & 84 & 0.3 & 0.3 & 0.3 & 0.3 & 0.2 & 0.3 & - & - & 104 \\
\hline \multicolumn{12}{|l|}{ Sediment; inter-tidal } \\
\hline NPP-2 outlet (27) & 26 & 421 & 21 & 20 & 26 & 26 & 12 & 0.5 & 1.2 & 4.2 & 849 \\
\hline \multicolumn{12}{|l|}{ Sediment; offshore } \\
\hline NPP-1 (46) & 1.0 & 283 & 14 & 15 & 14 & 17 & 8 & 0.2 & - & - & 564 \\
\hline NPP-2 (45) & 0.3 & 307 & 15 & 14 & 14 & 18 & 10 & 0.3 & - & - & 589 \\
\hline NPP-4 (40) & 10 & 197 & 20 & 17 & 15 & 21 & 5 & 0.4 & - & - & 546 \\
\hline
\end{tabular}

${ }^{a}$ Values listed are population mean activities in $\mathrm{Bq} / \mathrm{kg}$ based on dry weight for sediment and fresh weight for biota samples.

${ }^{\mathrm{b}} \Sigma \mathrm{A}=$ calculated "total" activity $={ }^{7} \mathrm{Be}+{ }^{40} \mathrm{~K}+\Sigma^{238} \mathrm{U}$-series $+\Sigma^{232} \mathrm{Th}$-series $+{ }^{137} \mathrm{Cs}+{ }^{54} \mathrm{Mn}+{ }^{60} \mathrm{Co}$, where $\Sigma^{238} \mathrm{U}$-series $=9 \times{ }^{214} \mathrm{~Pb}$ and $\Sigma^{232}$ Th-series $=2 \times{ }^{228} \mathrm{Ac}+7 \times{ }^{212} \mathrm{~Pb}$ (See text for details).

${ }^{\mathrm{c}}$ Including ${ }^{87} \mathrm{Rb}(0.11 \mathrm{~Bq} / \mathrm{kg})$ calculated from the law of constant proportion (between $\mathrm{K}$ and $\left.\mathrm{Rb}\right)$ for seawater.

d "_" indicates "not detectable".

Table 2. Comparison of average activities of artificial nuclides in various types/groups of environmental samples with their respective threshold values mandated by AEC

\begin{tabular}{|c|c|c|c|c|c|c|c|c|c|}
\hline \multirow[t]{2}{*}{$\begin{array}{l}\text { Type (and No. of } \\
\text { samples) }\end{array}$} & \multicolumn{3}{|c|}{$\begin{array}{l}\text { Average measured } \\
\text { Activity }(\mathrm{Bq} / \mathrm{kg})\end{array}$} & \multicolumn{3}{|c|}{$\begin{array}{l}\text { AEC-mandated } \\
\text { investigation level }(\mathrm{Bq} / \mathrm{kg})\end{array}$} & \multirow{2}{*}{$\frac{\text { Avg. }{ }^{137} \mathrm{Cs}}{\text { threshold }}$} & \multirow{2}{*}{$\frac{\text { Avg. }{ }^{54} \mathrm{Mn}}{\text { threshold }}$} & \multirow{2}{*}{$\frac{\text { Avg. }{ }^{60} \mathrm{Co}}{\text { threshold }}$} \\
\hline & ${ }^{137} \mathrm{Cs}$ & ${ }^{54} \mathrm{Mn}$ & ${ }^{60} \mathrm{Co}$ & ${ }^{137} \mathrm{Cs}$ & ${ }^{54} \mathrm{Mn}$ & ${ }^{60} \mathrm{Co}$ & & & \\
\hline Sea water (3) & 0.0024 & $-^{\mathrm{a}}$ & - & 2 & 40 & 10 & 0.0012 & - & - \\
\hline Algae (all 73) & 0.085 & 0.87 & 1.81 & 74 & 110 & 40 & 0.0011 & 0.008 & 0.045 \\
\hline NPP-1 (20) & 0.086 & 0.47 & 0.64 & & & & 0.0012 & 0.004 & 0.016 \\
\hline NPP-2 (46) & 0.089 & 1.17 & 2.60 & & & & 0.0012 & 0.011 & 0.065 \\
\hline NPP-4 (7) & 0.053 & - & - & & & & 0.0007 & - & - \\
\hline Fish (41) & 0.207 & - & - & 74 & 110 & 40 & 0.0028 & - & - \\
\hline Sediment (all 158) & 0.324 & 0.21 & 0.72 & 20 & 110 & 110 & 0.016 & 0.002 & 0.007 \\
\hline NPP-2 outlet (27) & 0.488 & 1.22 & 4.24 & & & & 0.024 & 0.011 & 0.039 \\
\hline Others (131) & 0.292 & - & - & & & & 0.015 & - & - \\
\hline
\end{tabular}

a "_" indicates "not detectable". 


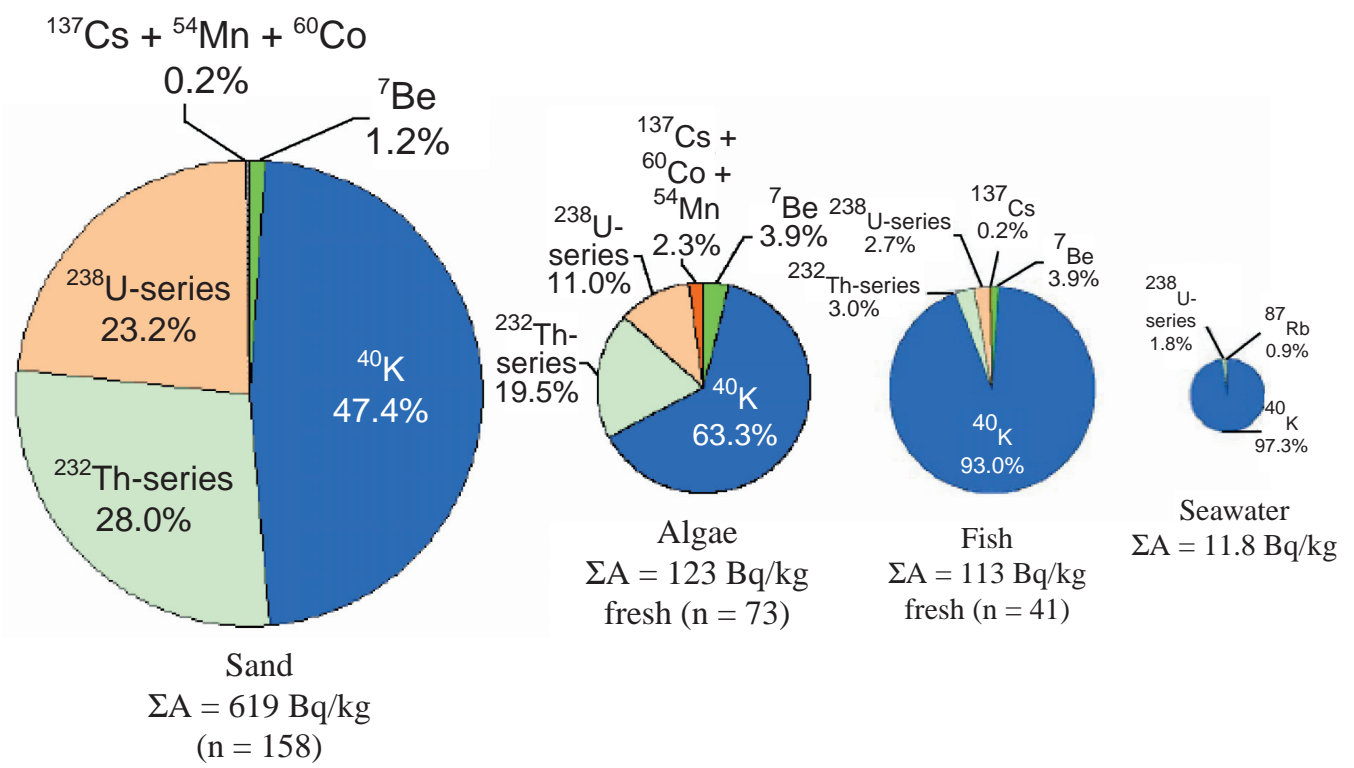

Fig. 4. Schematic presentation of the composition of nuclides and magnitude of average "total" activities in sediment, algae, fish and seawater samples.

than most of the values reported for the vast East China Sea Shelf in the distant north (Huh and $\mathrm{Su}, 1999 ; \mathrm{Su}$ and Huh, 2002) and the deep Okinawa Trough in the northeast of Taiwan (Lee et al., 2004). Compared with ${ }^{137} \mathrm{Cs}$ activities in soils of Taiwan (Huh and Su, 2004), especially northern Taiwan, the values reported here are also low. In view of this and the fact that ${ }^{134} \mathrm{Cs}$ cannot be detected in our samples, we believe the origin of ${ }^{137} \mathrm{Cs}$ in the north coast of Taiwan is primarily nuclear tests conducted by the U.S. and the former Soviet Union in the 1950's and 1960's.

\section{2. ${ }^{54} \mathrm{Mn}$ and ${ }^{60} \mathrm{Co}$}

${ }^{54} \mathrm{Mn}$ and ${ }^{60} \mathrm{Co}$ are two of the most commonly found neutron activation products resulting from the operation of nuclear reactors. Thus far, these two nuclides are found only in algae and sediment samples from the outlets of NPP-1 and NPP-2, indicating that the dispersal of anthropogenic nuclides is confined to the immediate vicinity of these two facilities.

The activities of ${ }^{54} \mathrm{Mn}$ and ${ }^{60} \mathrm{Co}$ in algae samples at the outlets of NPP-1 and NPP-2 have been closely monitored during the course of this program. The results (Fig. 5) show that the measured activities in samples from NPP-1 (up to $6 \mathrm{~Bq} / \mathrm{kg}$, averaging $0.6 \mathrm{~Bq} /$ $\mathrm{kg}$ for ${ }^{60} \mathrm{Co}$ ) are in general lower than those from NPP2 (up to $18 \mathrm{~Bq} / \mathrm{kg}$, averaging $2.6 \mathrm{~Bq} / \mathrm{kg}$ for ${ }^{60} \mathrm{Co}$ ). It could be due to that the outlet of NPP-1 is wider and more open to the ocean, facilitating the dissipation of anthropogenic contaminants in the discharged water.
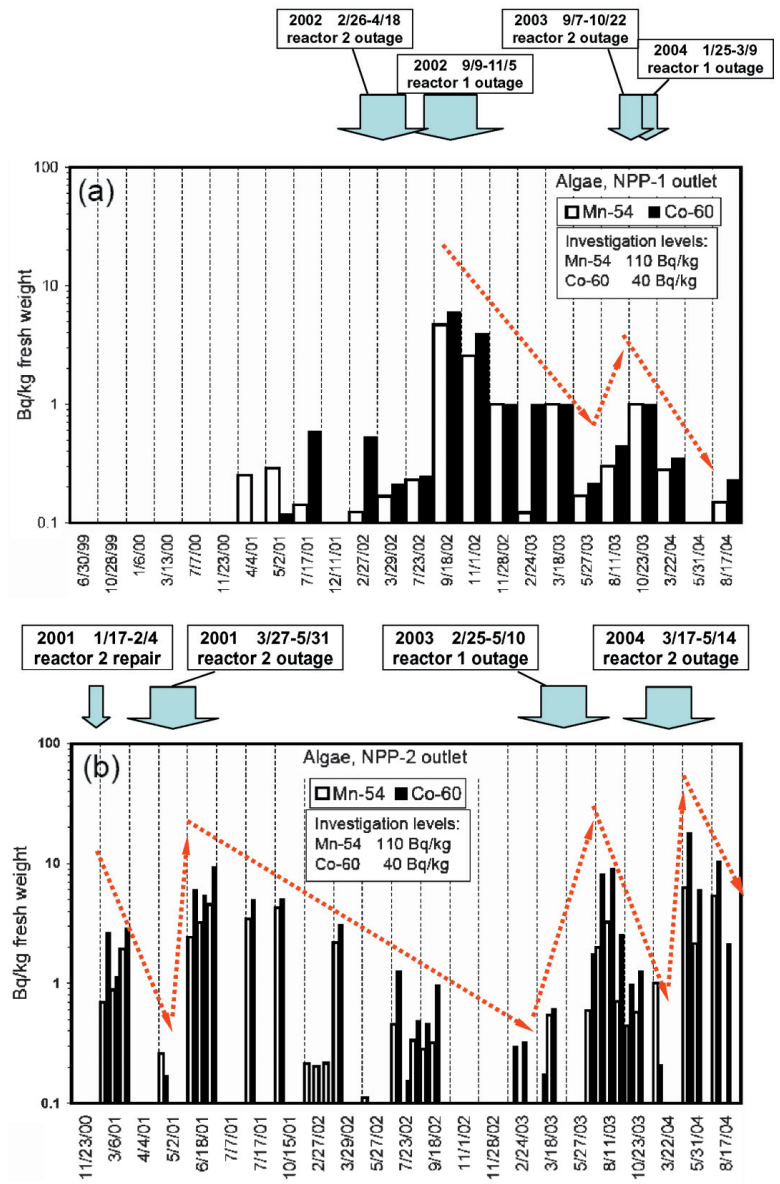

Fig. 5. Temporal variation of ${ }^{54} \mathrm{Mn}$ and ${ }^{60} \mathrm{Co}$ activities in algae samples from the outlets of (a) NPP-1 and (b) NPP-2. 
It is important to point out that the data shown in Fig. 5 reflect very well the operation history of the reactors in the two facilities, with the highs keeping pace with power outages for scheduled maintenance. The trend can be explained by the release of reactorgenerated artificial nuclides during or shortly after the maintenance period.

Although ${ }^{54} \mathrm{Mn}$ and ${ }^{60} \mathrm{Co}$ can be easily detected in algae samples from the outlets of NPP-1 and 2, the measured activities are well below the investigation levels of $110 \mathrm{~Bq} / \mathrm{kg}$ for ${ }^{54} \mathrm{Mn}$ and $40 \mathrm{~Bq} / \mathrm{kg}$ for ${ }^{60} \mathrm{Co}$ in this type of environmental samples (Table 2).

\section{ACKNOWLEDGEMENTS}

We are indebted to the collaboration of other components of this environmental monitoring program and the program coordinator, Prof. J.-S. Hwang. The fish samples were ashed at the Radiation Laboratory of Taiwan Power Company. S.-Y. Lee, S.-F. Lu, Y.-S. Tong, C.-Y. Ling, S.-T. Ho, L.-J. Shiao and Y.-K. Cheng assisted in field sampling and laboratory work. This work is supported by Taiwan Power Company.

\section{REFERENCES}

1. Huh, C.-A. and Su, C.-C., "Sedimentation Dynamics in the East China Sea Elucidated from ${ }^{210} \mathrm{~Pb},{ }^{137} \mathrm{Cs}$ and ${ }^{239},{ }^{240} \mathrm{Pu}$," Marine Geol., Vol. 160, No. 2, pp. 183-196 (1999).

2. Huh, C.-A. and Su, C.-C., "Distribution of Fallout Radionuclides $\left({ }^{7} \mathrm{Be},{ }^{137} \mathrm{Cs},{ }^{210} \mathrm{~Pb}\right.$ and $\left.{ }^{239,}{ }^{240} \mathrm{Pu}\right)$ in Soils of Taiwan," J. Environ. Radioact., Vol. 77, No. 1, pp. 87100 (2004).

3. Hwang, J.-S., Shao, K.-T., Cheng, I.-J., Hu, J.-H., Huh, C.-A., Fan, T.-H., and Lo, W.-T., Ecological Survey of Marine Environments Near Nuclear Power Plants in Northern Taiwan, Annual Report to Taipower Company (2000-2004). (in Chinese)

4. Lee, S.-Y., Huh, C.-A., Su, C.-C., and You, C.-F., "Sedimentation in the Southern Okinawa Trough: Enhanced Particle Scavenging and Teleconnection Between the Equatorial Pacific and western Pacific Margins," Deep-Sea Res. Part I, Vol. 51, pp. 1769-1780 (2004).

5. Su, C.-C., Huh, C.-A., and Chen, J.-C., "A Rapid Method for the Determination of ${ }^{137} \mathrm{Cs}$ in Seawater," Terrest., Atmos. Ocean. Sci., Vol. 11, No. 4, pp. 753-764 (2000).

6. Su, C.C. and Huh, C.-A., ${ }^{6210} \mathrm{~Pb},{ }^{137} \mathrm{Cs}$ and ${ }^{239,}{ }^{240} \mathrm{Pu}$ in East China Sea Sediments: Sources, Pathways and Budgets of Sediments and Radionuclides," Mar. Geol., Vol. 183, pp. 163-178 (2002). 